\title{
Preparation of a Novel 1:1 Copolymer of 4-Hydroxystyrene and Sulfur Dioxide
}

\author{
Tsutomu Shinoda, ${ }^{*}$ Mitsuhide YoshiKaWA, and Tohru NishiWaKI \\ Organic Division, Tokyo Metropolitan Industrial Technology Center, \\ Nishigaoka, Kita-ku, Tokyo 115, Japan
}

(Received June 19, 1995)

\begin{abstract}
KEY WORDS Acidity Function/Copolymerization/Nuclear Magnetic Resonance (NMR) Spectroscopy / Phenols / Polysulfone / 4-Trimethylsilyloxystyrene /
\end{abstract}

Recently, silylated hydroxystyrene monomers are being utilized to synthesize resist materials for microlithography. ${ }^{1}$ The authors in this study conducted the copolymerization of 4-trimethylsilyloxystyrene (1) and sulfur dioxide to prepare a silicon-containing positivetype photoresist. But the $1: 1$ copolymer of 1 and $\mathrm{SO}_{2}$ was readily hydrolyzed to give a novel sulfone polymer with phenolic hydroxyl groups. Polymer backbone $\mathrm{SO}_{2}$ groups may enhance the acidity of phenolic hydroxyl protons and facilitate hydrolysis of the trimethylsilyl groups.

We followed the copolymerization conditions of 4-trimethylsilylstyrene and sulfur dioxide reported by Matsuda et al. $^{2}$ Twice the molar quantity of distilled $\mathrm{SO}_{2}$ was transferred under vacuum into a reaction tube containing degassed monomer 1. After the monomer was dissolved, tert-butyl hydroperoxide (2) was added as the initiator and the solution was permitted to stand at $-80^{\circ} \mathrm{C}$ for $68 \mathrm{~h}$. The initiator to monomer mole ratio was $1: 10^{3}$. The reaction was terminated by cooling at $-196^{\circ} \mathrm{C}$ (liquid $\mathrm{N}_{2}$ ) and excessive $\mathrm{SO}_{2}$ was removed under vacuum. The solid residue, when exposed to air, changed color from white to bright purple but became colorless when dissolved in DMSO. The white polymer was isolated by precipitation in dichloromethane. The polymer was purified by reprecipitation and dried at $40^{\circ} \mathrm{C}$ in a vacuum oven until constant weight was reached.

The ${ }^{1} \mathrm{H}$ NMR spectrum of the polymer obtained is shown in Figure 1. ${ }^{3}$ No trimethylsilyl groups existed and the peak at $9.7 \mathrm{ppm}$ decreased in intensity by the addition of $\mathrm{D}_{2} \mathrm{O}$. Figure 2 shows the ${ }^{13} \mathrm{C}$ NMR spectrum of the polymer. ${ }^{3}$ In the aliphatic region of the spectrum,

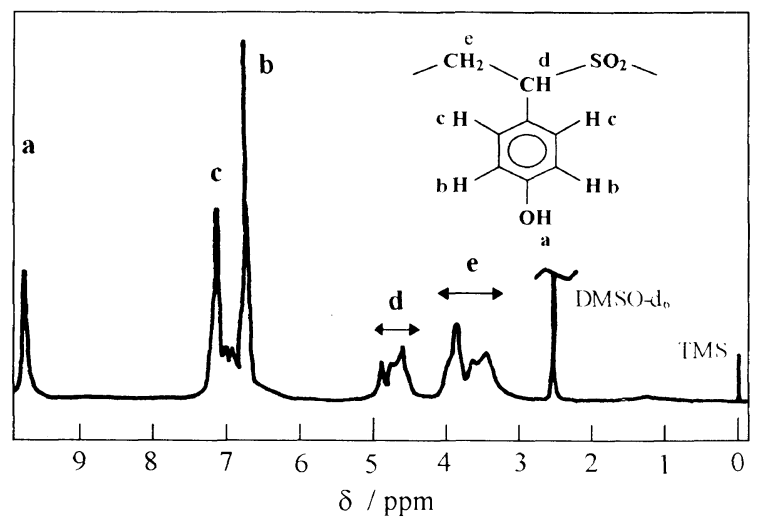

Figure 1. ${ }^{1} \mathrm{H}$ NMR spectrum of poly(4-hydroxystyrene sulfone). only two broad peaks were observed at $45.4-48.2 \mathrm{ppm}$ and $60.5-62.4 \mathrm{ppm}$ and assigned to methylene and methine carbons, respectively. ${ }^{4}$ The IR spectrum of the polymer exhibited absorptions at 1124 and $1311 \mathrm{~cm}^{-1}$ due to $\mathrm{SO}_{2}$ stretching (film from DMSO on $\mathrm{KBr}$ ). The polymer structure was thus a $1: 1$ copolymer of 4hydroxystyrene and $\mathrm{SO}_{2}$, poly(4-hydroxystyrene sulfone) (3). ${ }^{5}$ The yield was $77 \%$. Molecular weight and molecular weight dispersity of polymer 3 were determined as $M_{w}=76800$ and $M_{w} / M_{n}=2.84$ by gel permeation chromatographic (GPC) analysis. ${ }^{6}$ Results of thermogravimetric analysis (TGA) for polymer $\mathbf{3}$ are shown in Figure 3. Although rapid weight loss started at $130^{\circ} \mathrm{C}$ under $\mathrm{O}_{2}$ and $\mathrm{N}_{2}\left(5 \%\right.$ weight loss at $150^{\circ} \mathrm{C}$ in both

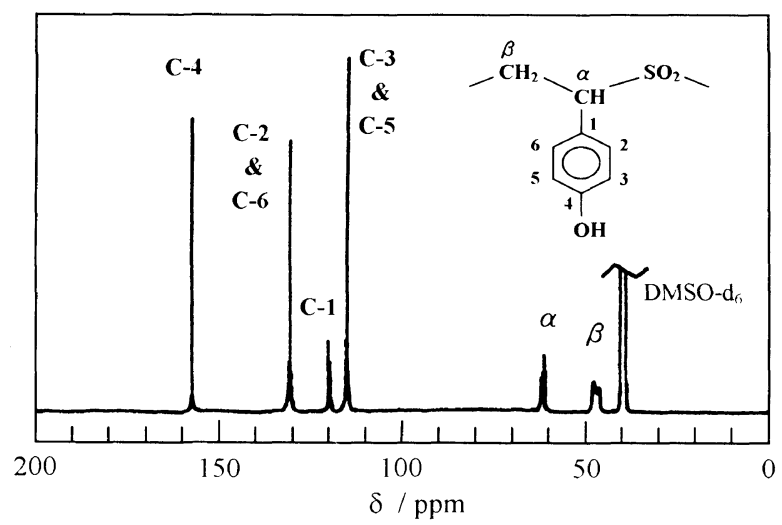

Figure 2. ${ }^{13} \mathrm{C}$ NMR spectrum of poly(4-hydroxystyrene sulfone).

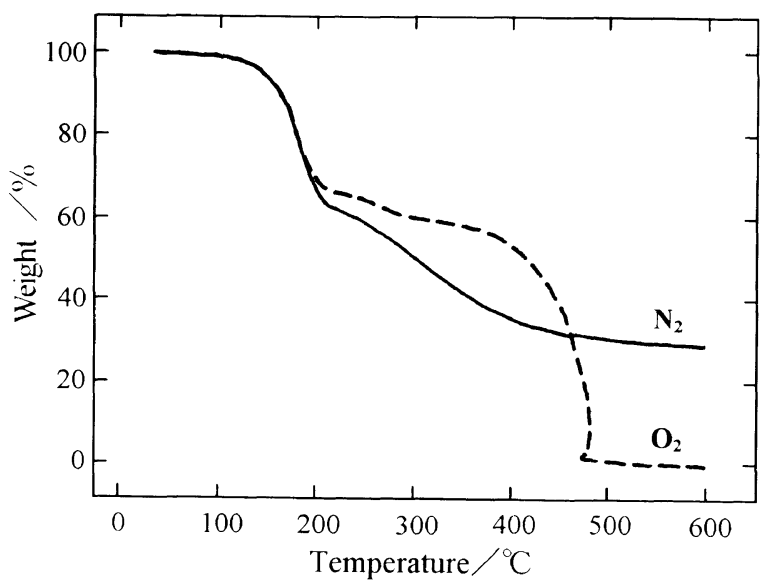

Figure 3. TGA curves for poly(4-hydroxystyrene sulfone) in oxygen and nitrogen atmosphere (heating rate $=10^{\circ} \mathrm{C} \mathrm{min}^{-1}$ ). 


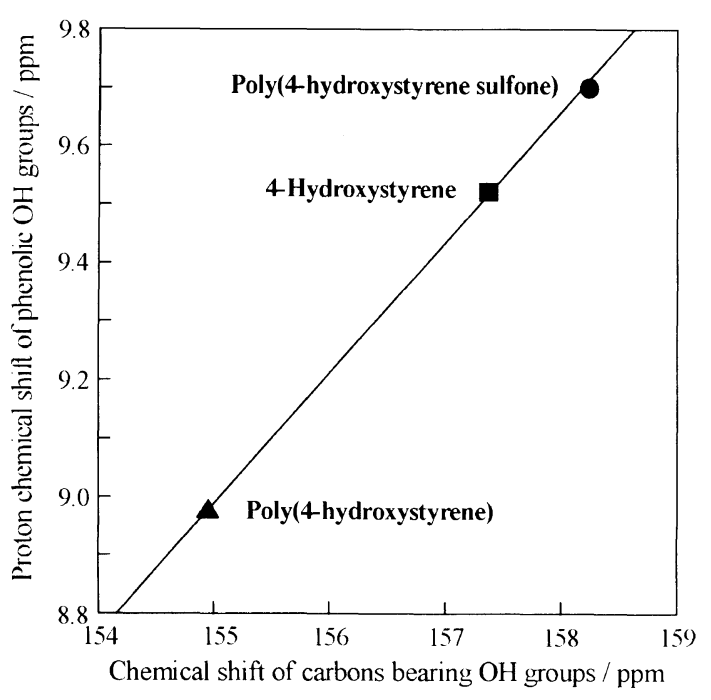

Figure 4. Relation between the chemical shifts of carbons substituted by hydroxyl groups and those of phenolic hydroxyl protons.

cases), the weight fraction of nonvolatile residue was much higher in nitrogen $\left(30 \%\right.$ at $\left.600^{\circ} \mathrm{C}\right)$.

The phenolic hydroxyl protons of polymer $\mathbf{3}$ are deshielded by $0.7 \mathrm{ppm}$ compared with those of poly(4hydroxystyrene) (4). The benzene ring protons are also deshielded and give two splitting peaks at 6.7 and $7.1 \mathrm{ppm}$, while those of 4 resonate between 6.1 and $7.1 \mathrm{ppm}$ in DMSO- $d_{6}$. Methine and methylene proton resonances are observed at $4.4-5.0$ and $3.1-4.1 \mathrm{ppm}$, respectively, and shift to much lower field than those of polymer 4 which resonate at $0.8-2.6 \mathrm{ppm}$. In addition, the C-4 carbon resonance shifts to $3.3 \mathrm{ppm}$ lower field than that of 4. All these changes can be attributed to the electron-withdrawing effect of the polymer backbone $\mathrm{SO}_{2}$ groups. Figure 4 shows a plot of the chemical shifts of phenolic hydroxyl protons against those of carbons substituted by phenolic hydroxyl groups for polymer $\mathbf{3}$, 4, and 4-hydroxystyrene. ${ }^{7}$ Good correlation is observed and implies that the acidity of $\mathbf{3}$ is enhanced. This enhancement probably causes hydrolytic cleavage of the trimethylsilyl ethers. ${ }^{8}$

Uhrich et al. ${ }^{9}$ synthesized a $3: 1$ copolymer of $\mathbf{1}$ and $\mathrm{SO}_{2}$ in a $4 \%$ yield and concluded that the propensity of the sulfone polymer to undergo hydrolysis may arise from difficulty to remove free $\mathrm{SO}_{2}$ completely from the material upon isolation. We carried out copolymerization reactions in the absence of initiator $\mathbf{2}$, and starting monomer 1 was recovered unchanged. When a drop of water was added to the starting mixture, the hydrolysis of monomer 1 occurred and poly(4-hydroxystyrene) was obtained as the main product in a $42 \%$ yield. These results indicate that hydrolysis of the trimethylsilyl groups does not occur only by mere contact with $\mathrm{SO}_{2}$, and that a copolymer of $\mathbf{1}$ and $\mathrm{SO}_{2}$ is produced as shown in scheme 1.

We also carried out the copolymerization of 4-tert-

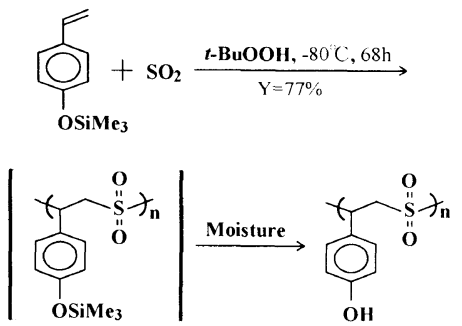

Scheme 1.

butyldimethylsilyloxystyrene, a more hydrolitically stable monomer than 1 , with $\mathrm{SO}_{2}$ at $-60^{\circ} \mathrm{C}$ for $70 \mathrm{~h}$. No sulfone polymer was produced and poly(4-tertbutyldimethylsilyloxystyrene) was obtained in a $78 \%$ yield with $M_{w}=37600$ and $M_{w} / M_{n}=2.24 .^{10}$

Acknowledgment. The authors thank Tosoh Co., Ltd. for GPC measurements of polymer 3 .

\section{REFERENCES AND NOTES}

1. H. Ito, A. Knebelkamp, and S. B. Lundmark, Polym. Mater. Sci. Eng., 68, 12 (1993); F. Bonfils, L. Giral, C. Montginoul, R. Sagnes, and F. Schue, Makromol. Chem., 193, 143 (1992).

2. H. Ito, T. Sakakibara, M. Matsuda, S. Ito, and H. Ono, Polym. Prepr., Jpn., 37, 3438 (1988).

3. ${ }^{1} \mathrm{H}$ and ${ }^{13} \mathrm{C}$ NMR spectra were recorded on a JEOL EX-400 spectrometer at a resonance frequency of $400 \mathrm{MHz}$ for proton and $100 \mathrm{MHz}$ for carbon-13. The spectra were observed at room temperature for a $0.40 \mathrm{~mol} \mathrm{dm}^{-3}$ solution in DMSO- $d_{6}$. The chemical shifts were referred to tetramethylsilane (TMS) added as an internal standard for proton and to DMSO- $d_{6}(39.5 \mathrm{ppm})$ and converted to the TMS scale for carbon- 13 .

4. The assignments were made by comparison with those published previously for poly(styrene sulfone) and both methine and methylene carbon resonances corresponded to the SMS monomer triad sequence ( $\mathrm{S}=$ sulfur dioxide; $\mathrm{M}=$ styrene); R. E. Cais, J. H. O'Donnell, and F. A. Bovey, Macromolecules, 10, 254 (1977).

5. By hydrolyzing poly[4-((tert-butoxycarbonyl)oxy)styrene sulfone]s, poly(4-hydroxystyrene sulfone)s have been synthesized with the mole ratio of 4-hydroxystyrene to sulfur dioxide not less than 2; R. S. Kanga, J. M. Kometani, E. Reichmanis, J. E. Hanson, O. Nalamasu, L. F. Thompson, S. A. Heffner, W. W. Tai, and P. Trevor, Chem. Mater., 3, 660 (1991).

6. GPC analysis of polymer 3 was performed with a Tosoh Model 8020 chromatograph equipped with two TSKgel $\mathrm{GMH}_{\mathrm{HR}}-\mathrm{H}$ columns and a refractive index detector. Reproducible chromatograms were obtained when $50 \mathrm{mmol} \mathrm{dm}^{-3}$ DMSO solution of lithium bromide was used as the eluting solvent. The molecular weight reported here is equivalent to that of pullulan.

7. The NMR spectra were measured at room temperature for a $0.20 \mathrm{~mol} \mathrm{dm}^{-3}$ solution in DMSO- $d_{6}$. Resonance peak tops of phenolic hydroxyl protons of each compound were observed with an error of less than $\pm 0.01 \mathrm{ppm}$, when measurements were made at $21-24^{\circ} \mathrm{C}$, within $\pm 10 \%$ variation of concentration, using a freshly opened ampule of Aldrich 99.9 atom $\%$ DMSO- $d_{6}$

8. Trimethylsilyl ethers of 4-hydroxystyrene and poly(4-hydroxystyrene) were stable enough to moisture to be handled in the air.

9. K. E. Uhrich, E. Reichmanis, S. A. Heffner, J. M. Kometani, and O. Nalamasu, Chem. Mater., 6, 287 (1994).

10. The eluting solvent was tetrahydrofuran. The molecular weight was polystyrene-equivalent. 